\title{
Factor Of Vendor Selection And Employees' Morale Towards Human Resource Outsourcing Decision In Organization
}

\author{
Tan Kok Hiean ${ }^{1}$, Irza Hanie Samah ${ }^{1 *}$, Aidanazima Abashah ${ }^{1}$, S. Nurshahrizleen ${ }^{1}$ and Nazmizan Muhammad ${ }^{2}$ \\ ${ }^{1}$ School of Business Innovation and Technopreneurship, UniMAP. \\ ${ }^{2}$ Faculty of engineering Technology, UniMAP.
}

\begin{abstract}
The purpose of this study is to investigate factor of vendor selection and employees' morale towards human resource outsourcing decision in organization. Study was conducted in Melaka within private organizations. Questionnaire was distributed and only 60 respondents were collected back. Data analysis was perform using SPSS version 21. Findings shows that employee's morale show high significant relationship $(r=0.761, p<0.05)$ with human resource outsourcing decision. Limitation and conclusion were discussed in this study.
\end{abstract}

\section{Introduction}

Nowadays, outsourcing is getting impetus in business corporations and organisations globally [1]. The majority of the companies tend to free from globalisation, their HR needs are becoming more complex and exacting, which is causing increased costs and more time and effort are required to take care of the employees. Therefore, cost is always persist a challenge to all the business organisations or enterprises to compete against their competitors by offering the best lower cost in total to end customers and to secure the market share in order to add value to the shareholders, especially in the competitive business environment and concurrently, facing the economic downturn [2]. They are always search for solutions and alternatives in order to stay competitive by reducing their costs and increasing their productivity [3].

Human Resource Outsourcing is the procedure of assigning and subcontracting human resource functions to an external vendor [4]. A remarkable current trend has been the detachment and transient labours, or the downright outsourcing of Human Resource activities were increasingly employed by the business organisations[5]. The multinational companies, business corporations from western countries, and the business process outsourcing (BPO) units in nations such as Malaysia, Russia, China and India even are expecting to outsource [4]. Reasons people to outsource their human resource because to focus on the core competencies of the business itself [6], reducing the cost of organization's operation, reducing headache of handling the issues of compliance, improving selection and recruitment, utilizing the resource efficiently [5].

Although human resource outsourcing activities have good reputation among organization, however there are some factors that organization need to consider when outsourcing their human resource especially when it comes to vendor. Every vendor providing unique outsourcing services depends on their culture and employees. Agent that have a similarity with the organization, outsourcing is likely to be success. Agent with different aim and goals may cause conflict and inefficiency. If your goals for outsourcing one or more functions aren't clear from the start, you can end up with a failed partnership. Next, employee's morale. Vendor that selected by the organization for outsourcing is consider as the third party beside the organization and employees. They are authorised on the human resource activities. Therefore, it will increase employee's insecurity, such as employee retention, performance appraisal, welfare, training which then will give an impact towards employee career development. Acording to [1] one third of human resource professionals are afraid of losing their job to work under vendors. At the same time, it will damage morale and motivation as jobs appear to be lost.

\section{Literature Review}

Human resource (HR) outsourcing is defined as the companies are transferring the administrative management of one of their most significant assets to third-party service vendor, which the third-party can 
take on the administration of hiring new personnel and at the same time, improve the running of employee benefits management [7]. Human resource (HR) outsourcing is also defined as the action of partially or wholly contracting human resource function out to external vendors and give them the permission to execute human resource activities (such as training, payroll, talent recruitment, etc.) for an organisation, in proportion to internal procurement seeing that the particular function is executed by the employees of the organisation [8].

HR activities that the organisations itself would otherwise commonly Provide [9]. In HR outsourcing, the human resource intermediaries (HRIs) will play the role which is focusing on delivering human resource (HR) services to both public sector organisations and private companies or firms (Kock et al, 2012). Due to globalisation, the competitive pressures is increased, the organisations are being surpassed by competitors in the business areas where they are not expert and concurrently, rapid organisational change [7][10]. When the organisations decide to engage in outsourcing, they decide to ally an external vendor to obtain their competencies to meet in a need for certain services of which the organisations think they cannot perform best [11]

The objective of outsourcing should be free up management and infuse confidence among them to take on more risk in the core areas of the business which are most gaining value [7]. processes can be redesigned to reach higher levels of productivity and effectiveness, which convert into increased profitability [7]. Outsourcing allows the management to focus more time, attention and resources on building the organisation's core business and competencies [7].

If the organisations require professionals and they are unaffordable to recruit or train them, HR outsourcing may be a solution, especially outsource functions where it can be hard to hire high-skilled personnel in the labour market [1], [7]Specialized vendors are more efficient because they can extend the costs of training personnel and carrying out research and development across more users [1]. There are five types of human resource functions outsourced to the external vendors which are recruiting process outsourcing (RPO), training and development, compensation and salary surveys, organisational design and development, human resource information system/information technology, and payroll [12].

Vendor management involves both vendor selection and client-vendor relationship control. Many researchers have addressed the latter issue by the employment of transaction cost theory [13] or the analysis of incomplete contracts [14]. The objective is for the client to induce the optimal performance from the vendors. It is important to select the right vendor for the right task. Failure of human resource outsourcing is when the vendor has lack of knowledge about outsourcing especially when it comes to selection process [15]. This issues have been addresses by many scholars but focusing on the performance data, whereby such approaches guarantee promising future results. Such approaches imply that vendors' past performance guarantees future results, an assumption does not necessarily apply because of ever changing technology, a high degree of heterogeneity of outsourced projects, intrinsic variation, and low predictability in vendor performance [16].

By recognizing the approaches of human resource outsourcing, can help organization to improve the decision to choose vendor selection. Two stage approach of vendor selection; whereby the first stage involves trial phase; which clients choose the right vendor for the right task, at this stage there is an existence of client-vendor interaction and this is where game theory is explained. In the second stage, this is where client chosen the vendor and employ for project implementation. [16]

There has been an argument about vendor selection is a way to reduce the supply risk that arise because of unreliable outsourcing. Despite, the multiple vendor also has been proposed as a means to reduce such risks [17] [18]. However multiple vendor which having different characteristic could have the potential to supply risk because the chances of either one of them to dominates is there[19]. Therefore, it depends on the organization to make decision on choosing vendor. Which the organization can choose more than one vendor for its organization but the vendors must understand the job and the task given, and must follow the nature of business of the organization.

Moreover, the selection of vendors and the determination of the task to be placed with those vendors are important decisions. Vendor selection decisions have a significant impact on the competitiveness of a firm, as purchases from vendors account for a large percentage of total costs for many firms. Selection of vendors has long been regarded as one of the most important functions to be performed by organizations because it is one of the organization's expenses. Vendor selection decisions are complicated by the fact that various criteria must be considered in decision making process. Most research on vendor selection has been descriptive or empirical in nature which involve in quantitative analysis with base on the performance [20] this research highlighted the human factors whereby the decision making of vendor selection is up to the top management. 
Previous study had mention that mostly company decision on vendor selections is based on the quantitative which something that they can see, however, none of them have addressed the issue of the quality [20] especially in subjective. Human resource outsourcing is considered as subjective matter, vendor need to connect and have the interaction with the clients so that they can understand what is the objectives that they need to deliver.

Employee's morale is defined as the "description of the emotions, attitude, satisfaction, and overall outlook of employees during their time in a workplace environment." It is implied that employee morale is thought to be directly related to part of effective productivity, which meant that the employees who are pleased and positive at work are considered to have high/positive morale while in contrast if employees who are unhappy and dissatisfied about their working environment are considered to have low/negative employee morale.

Zukin, \& DiMaggio (2012)[24] mentioned that human capital is the pivot around which organisational effectiveness can be resulted in comparison to financial capital and it is found to be tightly associated with the employee morale in the organisations in productivity and employee satisfaction. The essential of positive receptions in way of psychologically being well in working environment do make sense in altering scenario of different business proposition. Employee morale is frequently connected with the work setting, which is the psychological bonding of personnel with the firm which self-motivates them to behave and perform respectively.

There are actually consists of six reasons of the importance of employee morale which are improved productivity (the higher the morale, the higher the level of productivity); improved performance and creativity (the higher the morale, the better the performance, which is lead to more creativity of solutions found); reduced number of leave days (the higher the morale, the less the absenteeism, which high absenteeism will causes the corresponding loss in productivity; .higher attention to detail (when the morale is low, the employees will more likely to become distracted and unable to truly focus on work which might lead to the occurrence of mistakes and slower job schedule); a safer workplace (when the morale is higher, the employee will able to pay more attention to safety rules which could reduce the accidents happen in workplaces and increased quality of work (the higher the morale, the higher the effectiveness of performance and production, the better the quality produced.) [21]

The effect on employee morale and performance is considered as one of the dominant risk in human resource outsourcing [23] mentioned, outsourcing is impacting employee morale. Employees resist the outsourcing because of grudged to change (Franceschini et al., 2003). According to Gilley, Greer, \& Rasheed (2004). the research is studied about the issue about the effect of outsourcing movement on the employee's morale. Even though outsourcing has its benefits, the problems exist and can arise due to the dashed implementation of outsourcing arrangement (Power, 2006). Hence, the sudden restructuring in company and conflicting employee interests are a common factor turning up during outsourcing movement (Gilley, Greer, \& Rasheed, 2004).The result shows that, once the employee morale is lowered, less effort is contributed to the company and job satisfaction eventually suffers, and this have directly been linked to an increase effect on the absenteeism and ill-health (Gilley, Greer, \& Rasheed, 2004; Tekleab \& Taylor, 2003). This situation definitely creates a direct impact and correlated to the decreased in job productivity. Furthermore, employee openness to other jobs will start when the employee morale is hurt and decreased, which will causes the increased in labour turnover, which may lead to a large cost factor for organisations (e.g. future separation costs, new personnel learning costs and new personnel acquisition costs)[22].

According to Belcourt (2006), organisations do provide the employees with a sense of identification and feelings of security and belonging while outsourcing is a form of restructuring or reforming that always results in dismissed employees. Most of the professionals resist outsourcing because they may face the risk of losing their jobs, or may be forced to work for a vendor and worry that the administration and management think that the "outsiders" are more capable than them [1].

Outsourcing arrangement such as employees transferred to outsourcing, internal transfer (e.g. other functions), outplaced, offering voluntary retirements, or even the occurrence of redundancies and layoffs to staff, may causes the employees are acting against these arrangements, with their implication of "serfdom" in which the "bondmen" are sold as capital equipment). Outsourcing can bring about the disintegration of an organisation's culture which is alienating and "deskilling" employees instead of empowering and appreciating employees, at the moment, the transferred employees will experience emotional loss and culture changing [1]. All the employees start to suffer anxiety that may be caused by scare of lose their job in the next phase of outsourcing as well as the feeling of security is disrupted, which resulting in lost production once the rumours of outsourcing arrangements are spread [1] [11]. Hence, the managers will have to cope with the responses and reactions of dismissed employees [1] 
Based on the extensive of literature review, this research formulates the specific hypotheses are developed as follows:

$\mathrm{H}_{1}$ : There is a significant relationship between selection of vendors and effectiveness of HR outsourcing decision.

$\mathrm{H}_{2}$ : There is a significant relationship between employee's morale and effectiveness of HR outsourcing decision.

\section{Methodology}

150 Respondents were selected in this research where the respondents are the representative of the company which listed in private company in Melaka. Simple random sampling was adopted in this research, 60 respondents were collected back for data gathering. All questionnaires were collected over a period of 3 weeks. The response rate was $40 \%$. Questionnaire was designed using likert scale ranging from 1 to 5 from strongly disagree to strongly agree.

\section{Results and Discussion}

Quantitative research design was used in this study. Analysis and findings in this research was perform using SPSS version 21.

Respondents Background. The results present that are $75.0 \%$ are male respondents while the remaining $25.0 \%$ are female respondents. Other than that, the majority of the respondents were aged between 31-40 years old with $45.0 \%$ or 27 respondents while the least group is aged $18-30$ years old with $8.3 \%$ or 5 respondents only. There is also 15 respondents at the age between 41-50 years old which consist of $25.0 \%$, 7 respondents at the age between 51-60 years old which is $11.7 \%$ and 6 respondents which is $10.0 \%$ are at the age above 60 years old.

\section{Mean and SD Analyses.}

Mean and standard deviation values are presented in table 1 . The highest mean score was vendor selection $(\mathrm{M}=4.204, \mathrm{SD}=0.468)$, followed by employee's morale $(\mathrm{M}=4.113, \mathrm{SD}=0.483)$, and lastly human resource outsourcing $(\mathrm{M}=4.154, \mathrm{SD}=0.516)$.

Table 1.: Mean and SD Values

\begin{tabular}{|l|l|l|l|}
\hline Variables & $\mathrm{N}$ & Mean & SD \\
\hline $\begin{array}{l}\text { Vendor } \\
\text { selection }\end{array}$ & 60 & 4.204 & 0.468 \\
\hline $\begin{array}{l}\text { Employee's } \\
\text { morale }\end{array}$ & 60 & 4.113 & 0.48369 \\
\hline $\begin{array}{l}\text { Human } \\
\begin{array}{l}\text { Resource } \\
\text { Outsourcing } \\
\text { Decision }\end{array}\end{array}$ & 60 & 4.154 & 0.51686 \\
\hline
\end{tabular}

Correlation Analysis. Pearson correlation coefficient (r) was perform to test the relationship of independent variables (vendor selection and employee's morale) and dependent variables (Human resource outsourcing).

Table 2.: Correlation Analysis

\begin{tabular}{|l|l|l|l|}
\hline Variables & 1 & 2 & 3 \\
\hline $\begin{array}{l}\text { Vendor } \\
\text { selection }\end{array}$ & - & - & - \\
\hline $\begin{array}{l}\text { Employee's } \\
\text { morale }\end{array}$ & $0.761^{* *}$ & - & - \\
\hline $\begin{array}{l}\text { Human } \\
\text { Resource } \\
\text { outsourcing } \\
\text { decision }\end{array}$ & $0.595^{* *}$ & $0.647^{* *}$ & - \\
\hline
\end{tabular}

${ }^{* *}$ Correlation is significant at the 0.01 level (2-tailed)

The results shown are indicated that all of the independent variables involved in the analysis have strong relationships with the dependent variable, which all the values of correlation coefficient obtained for respective study variables are within the range between 0.50-0.69. Apparently, it can be concluded that all the hypotheses are considered accepted since all the study independent variables are having distinct positive correlation with the dependent variable (human resource outsourcing decision).

\section{Regression Analysis.}

result displays that the selection of vendors was found to be significant which the value is at a significance level of $1 \%$ (sig. $=0.249$ ) with beta value 0.182 . It can be considered that the selection of vendors has no significant relationship with the dependent variable, so the Hypothesis 1 (H1) is considered rejected. Simultaneously, the remaining study variable, which is employee morale is also determined to be significant at a significance level of $1 \%($ sig. $=0.013)$ with a beta value 0.354 . This result proved that a significant relationship subsisting between employee morale and effectiveness of human resources outsourcing decision, consequently, it means that the Hypothesis 2 (H2) is validated.

Based on the overall result of the multiple regression analysis, the value of $\mathrm{R} 2$ is 0.618 which indicates that the employee morale affects $61.8 \%$ of the effectiveness of human resource outsourcing decision. This shows that the result obtained from this research can provides an average explanation towards effectiveness of human resource outsourcing decision and the remaining percentage of $38.2 \%$ is influenced by other factors. Concurrently, the value of F is 22.24 and was found to be significant at significant at a significance level of $1 \%$. 
Table 3. Regression Analysis

\begin{tabular}{|l|l|l|l|l|}
\hline Variables & \multicolumn{3}{|l|}{$\begin{array}{l}\text { Human } \\
\text { Desicion }\end{array}$} & Resource Outsourcing \\
\cline { 2 - 5 } & Beta & Sig. & $\mathrm{R}^{2}$ & $\begin{array}{l}\text { Adjuste } \\
\mathrm{d} \mathrm{R}^{2}\end{array}$ \\
\hline $\begin{array}{l}\text { Vendor } \\
\text { selection }\end{array}$ & $0.182^{* *}$ & .249 & 0.618 & .0 .590 \\
\hline $\begin{array}{l}\text { Emplooyee } \\
\text { 's morale }\end{array}$ & $0.354^{* *}$ & .00 & & \\
\hline & & & & \\
\hline$* *$ Correlation is significant at the 0.05 level (2-tailed)
\end{tabular}

\section{Conclusion}

The result and finding of the research shows that it is essential for a business organization to consider about the factors that may influence the effectiveness of human resource decision. This is because factor such as employee's morale may cause ineffectiveness of human resource decision and bring negative impact to the business operation. Business may face crisis, loss or failure. Hence, when a business organization decided to outsource its human resources function, they should ensure that the vendor are able to understand all employees and the organization have to be smart to achieve effective human resource outsourcing.

This research consists of its limitation because it is conducted by using limited questionnaire survey as an instrument to collect data. The respondents may not be a true representation as a whole as the number of respondent are limited as 60 . Besides, the questionnaires are only conducted in single language, which is English language. It is possible to cause inaccurate in the result due to respondents may not truly understand all the questions and statements of the questionnaire especially the technical terms. This may cause misinterpretation of the statement, as a result causing confusion and inaccuracy.

\section{References}

[1] M. Belcourt, "Outsourcing - The benefits and the risks," Hum. Resour. Manag. Rev., vol. 16, no. 2, pp. 269-279, 2006.

[2] A. Islam, "ARTICLE DETERMINANTS OF OUTSOURCING DECISION IN THE MANUFACTURING INDUSTRY in BANGLADESH," Rev. Lit. Arts Am., vol. 5, no. January 2008, pp. 127-149, 2010.

[3] D. L. Caruth, S. S. Pane Haden, and G. D. Caruth, "Critical Factors in Human Resource Outsourcing," J. Manag. Res., vol. 12, no. 1, pp. 187-195, 2012.

[4] K. Mahmud, M. M. Billah, and S. M. R. Chowdhury, "Human Resource Outsourcing: A Study on Telecommunication Sector in
Bangladesh,” Int. J. Bus. Manag., vol. 7, no. 10, pp. 74-84, 2012.

[5] J. Woodall, W. Scott-Jackson, T. Newham, and M. Gurney, "Making the decision to outsource human resources.," Pers. Rev., vol. 38, no. 3, pp. 236-252, 2009.

[6] C. R. Greer, S. a. Youngblood, and D. a. Gray, "Human resource management outsourcing: The make or buy decision.," Acad. Manag. Exec., vol. 13, no. 3, pp. 8596, 1999.

[7] F. Franceschini, M. Galetto, a. Pignatelli, and M. Varetto, "Outsourcing: guidelines for a structured approach," Benchmarking An Int. J., vol. 10, no. 3, pp. 246-260, 2003.

[8] M. Tremblay, M. Patry, and P. Lanoie, "Human resources outsourcing in Canadian organizations: An empirical analysis of the role of organizational characteristics, transaction costs and risks," Int. J. Hum. Resour. Manag., vol. 19, no. 4, pp. 683-715, 2008.

[9] M. Seth and D. Sethi, "Human Resource Outsourcing: Analysis Based On Literature Review," Int. J. Innov. Manag. Technol., vol. 2, no. 2, pp. 127-135, 2011.

[10] H. Kock, A. Wallo, B. Nilsson, and C. Höglund, "Outsourcing HR services: the role of human resource intermediaries," Eur. J. Train. Dev., vol. 36, no. 8, pp. 772-790, 2012.

[11] P. Arroyo-López, E. Holmen, and L. De Boer, "How do supplier development programs affect suppliers?: Insights for suppliers, buyers and governments from an empirical study in Mexico," Bus. Process Manag. J., vol. 18, no. 4, pp. 680-707, 2012.

[12] E. Aktaş, I. Çiçek, and M. Kiyak, "The effect of organizational culture on organizational efficiency: The moderating role of organizational environment and CEO values," in Procedia - Social and Behavioral Sciences, 2011, vol. 24, pp. 1560-1573.

[13] L. . Willcocks, M. . Lacity, and T. Kern, "Risk mitigation in IT outsourcing strategy revisited: longitudinal case research at LISA," J. Strateg. Inf. Syst., vol. 8, no. 3, pp. 285-314, 1999.

[14] K. Nam, S. Rajagopalan, H. R. Rao, and A. Chaudhury, "A two-level investigation of information systems outsourcing," Communications of the ACM, vol. 39 , no. 7 , pp. 36-44, 1996.

[15] M. Bragg, Outsourcing: A Guide to selecting the correct business unit, Negotiating the contract. maintaining control of the process, vol. second edi. 2006.

[16] E. M. Snir and L. M. Hitt, "Vendor Screening in Information Technology Contracting With a Pilot Project," J. Organ. 
Comput. Electron. Commer., vol. 14, no. 1, pp. 61-88, 2004.

[17] R. Ernst, B. Kamrad, and K. Ord, "Delivery performance in vendor selection decisions," Eur. J. Oper. Res., vol. 176, no. 1, pp. 534541, 2007.

[18] C. a. Weber, J. R. Current, and W. C. Benton, "Vendor selection criteria and methods," Eur. J. Oper. Res., vol. 50, no. 1, pp. 2-18, 1991.

[19] R. V. Ramasesh, J. K. Ord, and J. C. Hayya, "Note: Dual sourcing with nonidentical suppliers," Nav. Res. Logist., vol. 40, no. 2, pp. 279-288, 1993.

[20] R. G. Kasilingam and C. P. Lee, "Selection of vendors - A mixed-integer programming approach," Comput. Ind. Eng., vol. 31, no. 1-2, pp. 347-350, 1996.
[21] D. L. Weakliem, "Morale and Workplace Performance," Work and Occupations, vol. 33, no. 3. pp. 335-361, 2006.

[22] M. Model, C. E. Michaels, and P. E. Spector, "Causes of Employee Turnover: A Test of the Mobley, Griffeth, Hand, and Meglino Model," J. Appl. Psychol., vol. 67, no. 1, pp. 53-59, 1982.

[23] Taylor, P. (2012). Renegotiating relationships with employees in outsourcing operations. People and Strategy, 35(1), 32.

[24] Taylor, P. (2012). Renegotiating relationships with employees in outsourcing operations. People and Strategy, 35(1), 32. 